\title{
Agro-climatic conditions of Uzbekistan and their compliance with the requirements of Chinese kale
}

\author{
SH. Asatov ${ }^{1, *}, U . \operatorname{Khurramov}^{1}, Z . \operatorname{Abdiev}^{1}$, and J. Karimov ${ }^{1}$ \\ ${ }^{1}$ Tashkent State Agrarian University, University str., 2, Tashkent province, Uzbekistan, 100140
}

\begin{abstract}
Expanding the range of vegetable crops due to the introduction of new non-traditional yields of vegetable crops is an urgent problem of modern vegetable growing. This article presents the results of the practical implementation of the possibility of introduction, as well as the development of elements for the production of Chinese cabbage in open and protected ground.
\end{abstract}

\section{Introduction}

The history of world plant growing in recent centuries clearly shows the enormous and often decisive role of the correct introduction of new cultivated plants [1]. Uzbekistan has favorable soil and climatic conditions for growing crops [2, 3]. However, the range of vegetables cultivated here is still not great. On $83 \%$ of the area occupied by vegetable crops, only 5 crops are cultivated: tomato, onion, cucumber, carrot and white cabbage. The total number of vegetable crops cultivated in the republic does not exceed 30 [4]. This indicates the need to expand the range of vegetable crops in the country, especially due to new vegetable plants, which open up wide opportunities for enriching the diversity of the diet and improving the quality of nutrition of the population [5].

In Uzbekistan, a disease such as iron deficiency anaemia is relatively widespread. Therefore, when expanding the range of vegetable crops, along with the content of biologically active substances in them, great importance should be given to the content of assimilable iron in them. In a market economy, it is important for vegetable producers to have income even outside the season. In this regard, it is important to determine the optimal sowing dates for growing in winter, autumn and early spring periods $[4,6]$.

One of these vegetable crops, characterized by a high content of biologically active substances and iron, suitability for cultivation in different periods of the year and early maturity, is the Pak Choi kale (Brassica chincosis L.) $[4,11]$.

Kale greens are widespread in Southeast Asia. In China, it occupies $25 \%$ of the area of vegetable crops. In Japan, Chinese and Peking cabbage are grown on an area of about 34 thousand hectares, and their gross harvest is more than 1.5 million tons [10-13]. It is widely cultivated in the United States, Western Europe, in the Far East of the Russian Federation. In the USA and European countries, it is cultivated fresh for preparing salads, and is also

* Corresponding author: sh.asatov@yandex.com 
used stewed, steamed, pickled and dried for cooking various dishes. Kale greens, like other types of cabbage, has a high nutritional value due to its high content of vitamins, mineral salts and many other biologically active substances with high therapeutic and prophylactic properties. It contains carbohydrates, proteins and pectin substances twice as much as white cabbage, vitamins $\mathrm{B}_{1}, \mathrm{~B}_{2}$, and $\mathrm{C}$ - twice as much as lettuce. It is a rich source of iron. With a daily requirement for iron of $10 \mathrm{mg}$, half of this amount can be provided by consuming $100 \mathrm{~g}$ of Chinese leaves daily. Along with iron, Chinese kale is able to accumulate selenium, cobalt, copper, which are active antioxidants, as well as sinirgine, which has an anti-concentrated effect [5, 9, 10-13].

High yield and early maturity are valuable qualities of Chinese kale. The first commercial product can be obtained from her 3 weeks after sowing. Its cultivation in the open field allows providing the population with vitamin products in the early spring period and in protected soil during the winter. It is more cold-hardy than Beijing cabbage and is less affected by diseases. It is unpretentious and requires simple farming techniques. It can be cultivated by sowing seeds directly into the ground. It is grown in any climatic conditions, light-requiring, but also tolerates shading and forms a high yield in warm weather and a short day $[11,13]$.

Therefore, the main purpose of our research was to study the effect of temperature conditions on the growth and development of Chinese kale plants, to establish the optimal timing for sowing seeds and planting seedlings in open and protected ground.

\section{Materials and methods}

In 2017-2018, on the basis of the training and experimental farm of the Tashkent State Agrarian University, studies were carried out to study the timing of sowing and planting of Chinese kale greens in various structures of protected ground and in two terms of planting open ground. For Central Asia, Chinese kale greens are an unconventional crop and there is no recommendation to establish the optimal timing of sowing and planting seedlings in open and protected ground.

The experiments were carried out in a period with short daylight hours: in the open field during early spring and autumn sowing (after March 10 and September 1), by seedling and seedling methods, and in protected - during winter sowing (late January - early February) by seedling method). In the open ground in conditions of medium loamy gray soils, the seeds were sown directly into the ground by mixing them with sawdust or sand. When growing seedlings, seedlings were first grown, at the age of 1-2 true leaves they were dived into containers with a cell diameter of 3-4 cm. At the age of 4-5 leaves, the seedlings were planted in the ground.

All experiments were carried out in 4-fold repetition with an area of the accounting plot of $1.4 \mathrm{~m}^{2}$, on which 40 plants were placed with double-row ribbon sowing according to the scheme $(60+10) \times 10 / 2 \mathrm{~cm}$. The experiments were accompanied by phenological observations, biometric records, taking into account the value of the total and marketable harvest.

\section{Results and discussion}

The main cultivation area for Chinese kale products is the suburban areas, which provide fresh produce to the urban population. Therefore, our research was carried out in the suburbs of Tashkent. The climatic conditions of this area are typical for the plain zone of the Tashkent province. 
The Tashkent province is located in the north-eastern part of the republic and is part of the Tashkent - Hungry steppe depression in the central part of Uzbekistan. Its territory is located between $42^{\circ} 17^{\prime}$ and $40^{\circ} 15^{\prime}$ north latitude and $68^{\circ} 39^{\prime}$ and $71^{\circ} 02^{\prime}$ east longitude and occupies the mountains and foothills of the Western Tien Shan, the valleys of the Angren and Chirchik rivers. It, as a part of the Turanian climatic province, belongs to the subtropical zone in terms of climate.

Since the research was carried out in the conditions of the flat part of the Tashkent province, below is a characteristic of its climate.

The climate of the plain zone of the region belongs to the foothill zone and is typical for the upper terrace of the Chirchik River, where most of the vegetable growing farms are located and is characterized by continental, abundant warmth and light, and aridity [4].

A large influx of solar radiation, combined with the peculiarities of atmospheric circulation, forms a continental type of climate with significant temperature fluctuations in the daily $\left(13.0-18.5^{\circ} \mathrm{C}\right.$ in summer and $5-10^{\circ} \mathrm{C}$ in winter) and the annual cycle (up to $30^{\circ} \mathrm{C}$ ) [5].

There is a very long sunshine here. It is $2,800-2,900$ hours per year, reaching $360-400$ hours per month in summer and dropping to 90-100 hours in winter. Days "without sun" are rarely observed: in December-January - from 10 to 25 in two months, from June to September - from 1 to 4 in 10 years. The duration of sunshine per day is 3-5 hours in winter and 12-13 hours in summer, with a day length of 8-9 and 15-16 hours, respectively $[1,2]$.

The average annual temperature is $+13-14^{\circ} \mathrm{C}$, the average monthly temperature in January is $-0.4-1.5^{\circ} \mathrm{C}$, in July $-+27-29^{\circ} \mathrm{C}$, the absolute minimum is $-28-35^{\circ} \mathrm{C}$, the absolute maximum is $+43-44^{\circ}$. The frost-free period lasts $216-230$ days. The average date of the last frost is March 20-26; the first autumn frost is October 19 - November 6. The duration of the period with active temperatures is above $5^{\circ} \mathrm{C}-268$ days (from March 15 to November 25), above $10^{\circ} \mathrm{C}-221$ days (from March 25 to October 31 ), above $15^{\circ} \mathrm{C}-173$ days (from April 14 to October 5). The sum of effective temperatures above $5^{\circ} \mathrm{C}-3,490^{\circ} \mathrm{C}$, above $10^{\circ} \mathrm{C}-$ $2,290^{\circ} \mathrm{C}$ and above $15^{\circ} \mathrm{C}-1,310^{\circ} \mathrm{C}[5,14]$.

The aridity of the climate is manifested in low rainfall and low air humidity in the summer months. Annual precipitation is $250-500 \mathrm{~mm}$. Mostly they fall in winter and spring. The wettest month is March. The relative humidity is $80-90 \%$ in winter and $30-40 \%$ in summer. The number of days with air humidity less than $50 \%$ is 180 . The number of days with snow cover is $25-70$ [14].

Consequently, the temperature and light conditions of the Tashkent province in certain periods are favorable for the growth of Chinese kale. The soil moisture deficit is compensated by the use of artificial irrigation.

The relative humidity of the air during the frost-free period is relatively low, and the greatest degree of its adverse effect on the Chinese kale is especially evident in the summer. Therefore, by analyzing long-term temperature readings and comparing them with the requirements of Chinese kale plants, it is possible to identify periods when this crop can be successfully grown.

It should be taken into account that the Chinese kale is a cold-resistant plant. It grows well at a temperature of $15-22^{\circ} \mathrm{C}$ at $25^{\circ} \mathrm{C}$, its growth is greatly delayed, the yield decreases, and the quality of the product deteriorates. This is an early ripening culture with a period from germination to production of 20-50 days. In the conditions of Uzbekistan, the period from sowing to technical ripeness for promising varieties is $42-46$ days. When planted with 20 day old seedlings, it is reduced by 22-23 days.

Relatively warm weather without severe frosts in the central zone of Uzbekistan lasts from early March to early November. Until the third decade of July, there is an increase up to the maximum average daily temperatures, and then their steady decline begins. In order to extend the period of receipt of production of Chinese kale from open ground, it can be 


\section{EMMFT-2020}

grown in several periods. To establish these terms, it is necessary to compare the average daily temperatures of various periods with the heat requirements of plants, taking into account the duration of the growing season. This is best done with a seedless growing method with a period from sowing to technical ripeness of 45 days. With the seedling method, during this period of time, you can grow this crop twice, having received two harvests per unit area.

Analysis of average daily temperatures during the warm season shows that kale can be grown during the first period from early March to early June (Table 1 and Figure 1).

Table 1. Meteorological conditions of the warm season of the flat zone of the Tashkent province

\begin{tabular}{|c|c|c|c|c|c|}
\hline 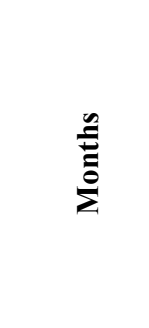 & 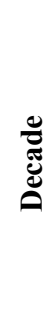 & 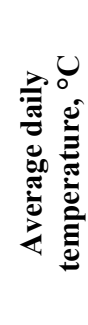 & 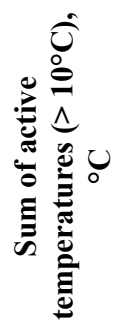 & 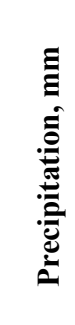 & 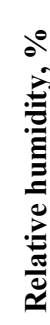 \\
\hline February & 3 & 3.5 & 0.0 & 20.9 & 59 \\
\hline \multirow{3}{*}{ March } & 1 & 5.4 & 0.0 & 28.9 & 63 \\
\hline & 2 & 7.9 & 0.0 & 26.7 & 61 \\
\hline & 3 & 9.9 & 0.0 & 30 & 62 \\
\hline \multirow{3}{*}{ April } & 1 & 12.5 & 25 & 27 & 62 \\
\hline & 2 & 15.1 & 51 & 23.9 & 61 \\
\hline & 3 & 16.8 & 68 & 21 & 59 \\
\hline \multirow{3}{*}{ May } & 1 & 18.2 & 82 & 16 & 58 \\
\hline & 2 & 19.9 & 99 & 13.3 & 54 \\
\hline & 3 & 21.7 & 117 & 10.5 & 50 \\
\hline \multirow{3}{*}{ June } & 1 & 24 & 140 & 6.3 & 46 \\
\hline & 2 & 25.5 & 155 & 2.8 & 43 \\
\hline & 3 & 26.7 & 167 & 2.7 & 41 \\
\hline \multirow{3}{*}{ July } & 1 & 27.2 & 172 & 1.4 & 42 \\
\hline & 2 & 27.3 & 173 & 1.4 & 44 \\
\hline & 3 & 27.2 & 172 & 1.6 & 45 \\
\hline \multirow{3}{*}{ August } & 1 & 26.3 & 163 & 0.9 & 47 \\
\hline & 2 & 25.5 & 155 & 1 & 47 \\
\hline & 3 & 23.7 & 137 & 0.8 & 47 \\
\hline \multirow{3}{*}{ September } & 1 & 22 & 120 & 0.7 & 47 \\
\hline & 2 & 20.1 & 101 & 0.8 & 48 \\
\hline & 3 & 17.8 & 78 & 2.4 & 49 \\
\hline \multirow{3}{*}{ October } & 1 & 15.8 & 58 & 7.4 & 53 \\
\hline & 2 & 13.5 & 35 & 10.1 & 55 \\
\hline & 3 & 11.7 & 17 & 15.4 & 58 \\
\hline
\end{tabular}



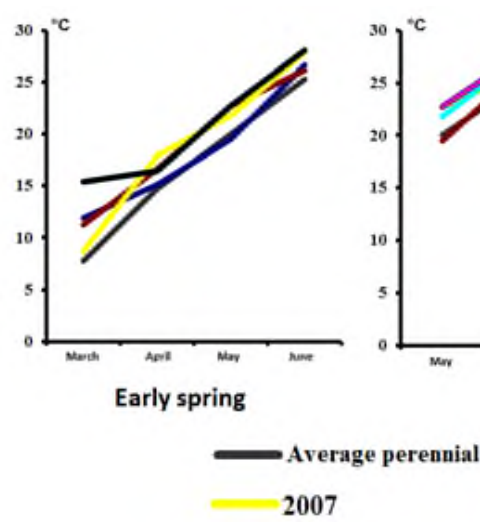
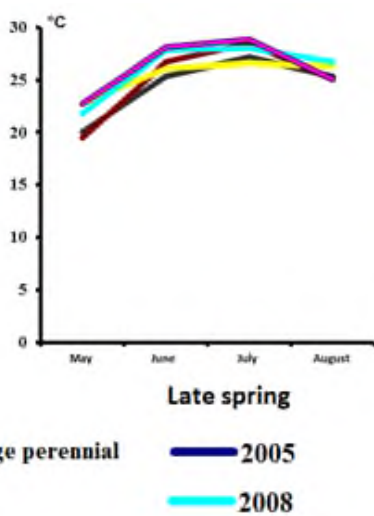

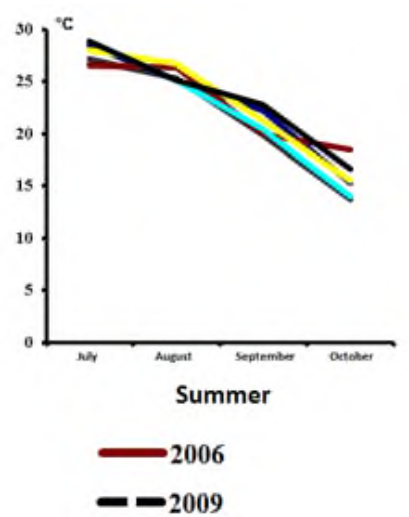

Fig. 1. Average daily air temperature $\left({ }^{\circ} \mathrm{C}\right)$ in different periods of the warm season in the flat zone of the Tashkent province

To grow a full-fledged crop before the end of May, the last calendar sowing date must be on April 15th. The first sowing date can be done in early March and re-sowing in 10-15 days until April 15.

With the seedling method, in which 22-24 days are required from planting to technical ripeness, the last spring time for planting seedlings falls on the end of the first decade of May. The first spring planting of seedlings can also be carried out from the beginning of March at the first opportunity to go into the fields.

From the beginning of June to the third decade of August, the temperature is unfavorable for Chinese kale greens, reducing its yield and deteriorating product quality. Growing this culture during this period is difficult, not very effective and not always advisable.

Along with unfavorable temperature conditions, the period from early June to mid-August is characterized by the lowest relative air humidity (below 50\%), which is also unfavorable for kale.

In the autumn, the temperature is favorable for Chinese kale. In a seedless culture, sowing can begin in mid-August and last sown in mid-September.

In a seedling culture, planting seedlings can be started from the beginning of September, and the last time to plant it in the second five days of October. At the same time, the plants are not oppressed by the intense heat, which happens in the late spring period, and the optimal air humidity contributes to good plant growth.

Growing at different temperatures and different relative air humidity, the plants of Chinese kale, with different methods and periods of cultivation, form an unequal vegetative mass and give an unequal yield per unit area (Table 2).

Table 2. Growth and yield of Chinese kale greens of 'Sharq Guzali' variety with different methods and timing of cultivation (2017-2018)

\begin{tabular}{|c|c|c|c|c|c|c|c|}
\hline \multirow[b]{2}{*}{ 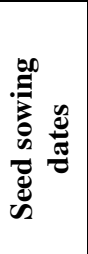 } & \multirow[b]{2}{*}{ 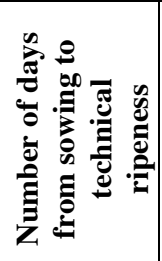 } & \multirow[b]{2}{*}{ 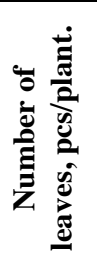 } & \multirow[b]{2}{*}{ 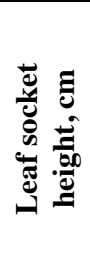 } & \multirow[b]{2}{*}{ 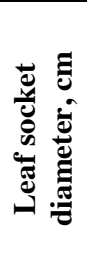 } & \multicolumn{3}{|c|}{ Productivity, kg/m² } \\
\hline & & & & & 2017 & 2018 & Average \\
\hline
\end{tabular}




\begin{tabular}{|c|c|c|c|c|c|c|c|c|}
\hline 20.01 & 46 & 9.0 & 31 & 313 & 157 & 3.9 & 4.2 & 4.05 \\
\hline 21.02 & 44 & 10.0 & 33 & 333 & 172 & 3.4 & 4.6 & 4.00 \\
\hline 1.02 & 47 & 9.0 & 28 & 218 & 144 & 3.6 & 3.8 & 3.70 \\
\hline \multicolumn{10}{|c|}{ Growing under film tunnels } \\
\hline 10.02 & 65 & 5.5 & 14.5 & 11.0 & 110 & 2.1 & 2.4 & 2.35 \\
\hline 20.02 & 57 & 7.0 & 20.0 & 15.0 & 137 & 2.8 & 2.7 & 2.75 \\
\hline \multicolumn{10}{|c|}{ Op ground - early spring sowing } \\
\hline 10.03 & 53 & 7.5 & 15.5 & 18.5 & 149 & 2.6 & 2.8 & 2.70 \\
\hline 20.03 & 45 & 6.5 & 12.5 & 13.5 & 132 & 2.4 & 2.1 & 2.25 \\
\hline \multicolumn{8}{|c|}{ Open ground - late summer sowing } \\
\hline 1.08 & 43 & 6.5 & 22.5 & 17.5 & 153 & 3.8 & 3.5 & 3.65 \\
\hline 15.08 & 45 & 9.5 & 27.5 & 31.5 & 135 & 4.6 & 4.9 & 4.75 \\
\hline 1.09 & 50 & 8.0 & 24.5 & 28.0 & 167 & 4.1 & 3.8 & 3.95 \\
\hline
\end{tabular}

The highest yield of Chinese kale greens in Uzbekistan, forms during late summer sowing (August 15) and when grown in greenhouses $\left(4.0-4.75 \mathrm{~kg} / \mathrm{m}^{2}\right)$, where temperature and relative humidity are regulated. Early spring sowing dates for this crop are less productive, but give a sufficiently $\left(2.25-2.70 \mathrm{~kg} / \mathrm{m}^{2}\right)$ high yield.

\section{Conclusion}

Both in protected and in open ground, it can be grown both in a seedless and seedling way. It is better to grow seedlings in a pot method and plant in a permanent place at the age of 15-20 days with 4-5 true leaves.

The period from germination to receipt of production of Chinese kale is $20-50$ days. In protected ground, sowing seeds for seedlings should be carried out in December-January every 10-15 days, in open ground - in the second half of March - early April and early September.

Harvesting should be carried out in any phase of growth - from the formation of 4-5 true leaves to the beginning of the formation of flowering shoots, cutting off plants at a height of 2-3 $\mathrm{cm}$ above the soil surface.

The highest yield of leaves of Chinese kale can be obtained using film greenhouses (4.0 $\mathrm{kg} / \mathrm{m}^{2}$ ), and in the open field, the highest yield of $4.75 \mathrm{~kg} / \mathrm{m}^{2}$ ), is formed in late sowing.

\section{References}

1. S. Isaev, I. Begmatov, G. Goziev, S. Khasanov, IOP Publishing 883(1), 012080 (2020)

2. S. K. Isaev, R. U. Rakhmonov, S. S. tadjiev, G. I. Goziev, S. Z. Khasanov, IOP Publishing 614(1), 012147 (2020)

3. N. Teshaev, B. Mamadaliyev, A. Ibragimov, S. Khasanov, InterCarto. InterGIS 26(3), 324-333 (2020)

4. O. V. Averchaeva, V. V. Chub, Floriculture 2, 46-49 (2010)

5. K. U. Holmamatovich, A. S. Ismatovich, Problems and solutions of advanced scientific research 1(1), 18-22 (2019)

6. L. L. Bondareva, Potato and vegetables 2, 22 (2009)

7. L. L. Bondareva, P. F. Kononkov, Potato and vegetables 2, 20-21 (2018)

8. N. A. Glubkina, Vegetables of Russia 1(2), 61-67 (2008)

9. V. P. Grin, S. V. Kuznetsov, Rare vegetable and spicy crops, 24-27 (2001)

10. K. H. Lin, F. C. Shih, M. Y. Huang, J. H. Weng, Plants 9(8), 960 (2020) 
11. Cabbage Plant, 113 (Yunivest Media Press, Kiev, 2009)

12. D. Šamec, B. Urlić, B. Salopek-Sondi, Critical reviews in food science and nutrition 59(15), 2411-2422 (2019)

13. K. H. Kim, S. O. Chung, Journal of Biosystems Engineering 43(1), 30-36 (2018)

14. R. A. Kulmatov, S. A. Adilov, S. Khasanov, IOP Publishing 614(1), 012149 (2020) 